\title{
Research on Teaching Reform in Swimming Class Under Scenario of Modular Platform
}

\author{
Xing-biao $\mathrm{CHEN}^{1, \mathrm{a}}$ and Rui $\mathrm{XI}^{2, \mathrm{~b} \text {,* }}$ \\ ${ }^{1}$ Sports Department, Beijing Jiaotong University,Beijing,China \\ ${ }^{2}$ School of economics and management, Beijing Jiaotong University, Beijing, China \\ abjtuxingbiao@163.com,b18120711@bjtu.edu.cn \\ ${ }^{*}$ Corresponding author
}

Keywords: teaching reform, modular platform, class experiment, interest guidance

\begin{abstract}
The traditional teaching in swimming class has neglected differences of students in swimming foundation, which will prevent individual development. The modular platform of automotive filed that is applied to swimming teaching has created four modules of familiarity with ability in swimming, body control, essential exercise and integrated coordination to match contents, methods and evaluation system. This reform has effectively eliminated limitations of hierarchical teaching mode, promoted ability matching with interest, improved teaching effects and formed propagable and replicable teaching mode.
\end{abstract}

\section{Introduction}

The general secretary Xi Jinping stated in National Conference on Education 2018, "we shall establish the educational concept of "Health First", offer enough physical education classes and help students enjoy the pleasure, strengthen physique, cultivate perfect personality and will in physical exercise [1]". The close combination between sports and education will promote comprehensive development of students and cultivate high-level talents for the society. at present, universities and colleges in China still offer traditional swimming class, which will teach new swimming skills for the most of students, but not promote individualized development. As a result, students with different learning levels cannot learn and develop completely, which has limited swimming skills of students and prevented development of students' strong points and formation of good hobbies and interests.

\section{Literature Review}

To explore effective and feasible class reform and offset current disadvantages of swimming class, Peng Xiao and Jia Kai et al applied task-driven teaching method to teaching practice of compulsory swimming course for PE major in universities and technical colleges from the view of cooperative teaching [2,3]. Li Jiahong et al implemented blended teaching for swimming class in sports institute and combined traditional teaching of swimming class with advantages of online teaching [4,5]. Over recent years, many scholars have proposed hierarchical teaching method [6,7], which describes to group students based on their essential skill level, design different teaching solutions based on learning level of students and select appropriate teaching methods. Although hierarchical teaching theory is excellent, according to existing literature, current teaching reform requires to implement prior examination and class grouping for teaching hierarchy, which has conquered disadvantages of traditional teaching mode for individualized development. Meanwhile, hierarchical method is also influenced by number of students, number of classes and teaching hours, resulting limitations for results of hierarchical teaching. Therefore, under current conditions, it is an important research topic to realize teaching reform in swimming class through building proper course system and combining with corresponding contents, methods and evaluation system.

\section{Research Model}

Modular platform has been widely used in many fields, of which the greatest advantage is to 
organically combine with changes and has presented high flexibility and saved costs. In automobile manufacturing field, it is defined as the carrier that is combined with various general modules for multiple product platforms [8]. The modular platforms in automobile manufacturing industry, for example, Volkswagen MQB, BMW UKL and Benz MFA, and LEGO toys are successful examples of development of modular platform $[9,10]$. Under guidance of hierarchical teaching theory, we have transformed the system of swimming class from simple skill teaching to swimming survival skill plus skill teaching based on teaching requirements of elementary swimming course and created four clear learning modules, including familiarity with ability in swimming, body control in water, essential exercise and skill coordination. These four modules connect and support with each other to build an integrated teaching system for swimming class.

The 1st module is familiarity with ability in swimming, which is the first stage for beginners. It is designed for beginners to experience buoyancy, pressure and resistance, gradually feel water environment, eliminate fear and cultivate interest for swimming to lay foundation for learning various swimming skills. It mainly includes theoretical basis of swimming safety and self-rescue, entering water pool independently, walking in water, opening eyes in water, tuck and body floating, body floating and standing in water.

The 2nd module is body control, which mainly includes two steps. Front and back rolling requires to grasp force of individual body part in water; experience breathing method in water, make breathing exercise and preliminarily experience breathing method during swimming (breathing process, action and rhythm), enhance tuck position, body floating and standing position and enhance confidence for body control in water. The pulling-off sliding step requires students to experience and grasp horizontal position of body and streamline position and improve the ability of controlling body in water to lay a solid foundation for learning various positions.

The 3rd module is essential exercise which focuses on leg actions. Compared with other swimming modes, leg actions of breaststroke will generate pushing force while maintaining body balance. It mainly includes ground breaststroke leg exercise, sliding in water plus once breaststroke leg position exercise, fender pulling-off and breaststroke leg position exercise, and once breathing, sliding in water plus multiple breaststroke leg positions exercise.

The 4th module is integrated coordination which requires coordination between breaststroke hands and breathing to finish a complete set of breaststroke actions. This module mainly includes once breathing plus single breaststroke leg position, once breathing plus multiple breaststroke leg positions, and integrated breaststroke skill (breaststroke long arm pull skill, breaststroke rolling skill, and breaststroke starting skill).

\section{Research Design}

From the view of teaching process design, this research has developed and operated modular platform from teaching contents, teaching methods, teaching arrangement and evaluation of teaching results to deploy teaching reform.

\subsection{Teaching contents}

The teaching contents generally focus on combination between theories and practices. From the view of theory, we have built swimming teaching platform focusing on four modules, strictly executed steps of each module and introduced the four teaching modules in the first class to help them understand teaching contents and forms required for the whole class clearly and arouse their enthusiasm for new modules. From the view of practice, we have divided integrated modules, after teaching and learning for each module, executed module assessment. The module assessment has definite requirements that students who have qualified performance shall learn new module, otherwise, learn original module. As a result, students with different learning levels can learn in the same class. When learning for the 4th module ends, final assessment will be executed

\subsection{Teaching method}

Teaching method is a comprehensive representation of teaching form, which is constituted by 
teaching theory, teaching awareness and teaching strategy, etc [11]. This paper has applied accurate and interactive teaching which, firstly, enables students to understand teaching contents and their conditions at the beginning of class, at the end of each module and at the beginning of the next module to realize teaching objectives; second, integrates with different characteristics of students through modular platform, enables students to present their learning results and build platform for mutual learning; third, through multi-media, records examination results for each module, encourages students to watch videos after class and correct their errors and learn the next module better; finally, builds after-class learning platform (for example, swimming club, swimming association and organization) to improve learning results and hours.

\subsection{Teaching arrangement}

Teaching arrangement is not limited to traditional teaching hours, but applicable to 32-hour, 48hour and 64-hour, etc. There is not definite requirement for learning time of each module. However, it depends on assessment performance for each module. We take 32-hour for an example. Teachers will generally allocate learning time for each stage upon $6+7+9+10$ to ensure integrated results.

\subsection{Evaluation of teaching results}

The evaluation of teaching results is mainly constituted by final examination and evaluation, performance for each module and self-evaluation (See Table 1).

Table 1. Rating for teaching results.

\begin{tabular}{|c|c|}
\hline \multicolumn{2}{|c|}{ Evaluation of teaching results } \\
\hline \multicolumn{2}{|c|}{$\begin{array}{l}\text { Teacher's final examination and } 60 \% \\
\text { evaluation }\end{array}$} \\
\hline Performance for each Module 1 & $5 \%$ \\
\hline \multirow[t]{2}{*}{ module } & $5 \%$ \\
\hline & $5 \%$ \\
\hline Student's self-evaluation & $25 \%$ \\
\hline Total & $100 \%$ \\
\hline
\end{tabular}

Teacher's final assessment for students will be $60 \%$ of total score. It aims to investigate overall conditions of students, evaluate their advantages and disadvantages and promote after-class learning. The evaluation for each module will be $5 \%$ of the total score and will arouse their enthusiasm for overall learning progress. Students' self-evaluation will be $25 \%$ of the total score. Through comments for each module and students' self-evaluation, we can clearly present teaching results, stimulate students to learn actively, change passive learning mode and improve teaching results.

\section{Result}

\subsection{Definite teaching standards and process}

The application of modular platform has defined teaching steps, which will help teachers clearly grasp teaching progress and help students understand tasks of each module. Clear module assessment standards have shortened target period, which will strengthen students' understanding for swimming knowledge, finally improve their abilities in swimming and increase swimming distance.

\subsection{Match students' abilities with their interests}

American psychologist Broome stated in The Theory of Mastery Learning, "due to lack of appropriate teaching conditions and targeted support, many students have bad performance, instead of limitation of intelligence level [12]". Therefore, finding out large differences in swimming bases and fuzzy understanding level for class modules will promote to make reform solution complying with era development from the view of students. The blended teaching has cultivated self-learning ability and interests, realized transformation from passive learning to active learning, aroused students' enthusiasm for learning and improved their abilities for knowledge and skills. 


\subsection{Harmonious interaction between teachers and students in teaching process}

Due to modular teaching, students will select the module applicable to their learning level successfully, which has increased opportunity to communicate with teachers and shorted the distance between teachers and students. Students with equivalent learning skill learn together and communicate with each other. When communicating with the teacher, students will have more opportunities to ask questions and find out their defects and shortcomings, which will promote good relationship between teachers and students, forming positive cycle for teaching and learning.

\subsection{High-efficient teaching results of modular platform}

The modular platform has divided teaching tasks, which will greatly improve exercise efficiency and optimize teaching results. The course selection system has not differentiated learning bases for swimming, resulting in large gap in swimming skills and influencing final assessment. The modular platform will differentiate students based on their learning levels to further enhance swimming skills. As a result, they can try longer swimming distance and more items such as treading position. Meanwhile, students who have weak learning bases or learn swimming recently will have more time to lay a solid foundation to realize individualized development.

\subsection{Popularize modular platform mode}

The teaching for swimming class under scenario of modular platform proposed in this paper can be widely popularized. Such teaching method has firstly avoided limitations of hierarchical teaching for number of classes, reserved original course selection system in most of universities and declined resistance and difficulties for reform. Second, such mode is not limited to class hours. It can change and adjust upon different scores and teaching hours to apply to elementary class, intermediate class and advanced class. Good teaching results have been seen.

\section{Conclusion}

The establishment of modular platform for swimming class will realize objectives of modern teaching reform in swimming class of universities. As a result, teaching tasks will be completed properly and effectively in limited teaching hours, besides, each module will play its role to satisfy with requirements for individualized learning and development through platform combination. In addition, avoiding limitations of hierarchical teaching mode, the modular platform will completely consider differences in learning bases, clearly present knowledge system of each module, guide students to find problems, explore and innovate, and cultivate the ability of solving problems independently, thus to arouse their enthusiasm for sports and lay solid foundation for lifelong learning.

In actual class, one teacher may be responsible for teaching four students, which requires higher teaching ability. Meanwhile, due to differentiation for different modules, some students may present weak learning ability and high psychological fluctuation. As a result, constant improvement is required in teaching reform.

\section{Acknowledgment}

This research was financially supported by the Teaching Reform and Construction Project of Beijing Jiaotong University- "Study on the Application of Segmented Teaching Assessment in Swimming Teaching Class" (20190424)

\section{References}

[1] Hao Mengjia, Xiong Xu. "Adhere to the path of educational development of socialism with Chinese characteristics and cultivate socialist builders and successors with comprehensive development in morality, intelligence, physique, beauty and labor" [EB/OL]. http://edu.people.com.cn/n1/2018/0911/c1053-30286253.html, 2018-09-11. 
[2] Peng Xiao. "Experimental research on application of task-driven teaching method to swimming teaching for PE major of universities" [D]. Hebei Normal University, 2019.

[3] Jia Kai. "Experimental research on cooperative teaching mode for swimming optional course in Changchun Guanghua University" [D]. Northeast Normal University, 2014.

[4] Li Jiahong, Guan Caixia, Ling Min. "Innovative research on individualized teaching mode for swimming class under IT environment" [J]. Journal of Guangzhou Sport University, 2017(4).

[5] Song Kangkang. "Evaluation research on teaching results of blended teaching to swimming class of sports institute" [D]. Shandong Sports Education, 2018

[6] Jiang Wei. "Functions of hierarchical teaching in swimming class of universities" [J]. Sports World (Scholarly), 2017(05):125-126.

[7] Hou Sai, Zhou Hongtao. "Practical application of hierarchical teaching to swimming teaching in universities" [J]. Learning Weekly, 2019(12):24-24.

[8] Zhao Fuquan, Liu Zongwei, Li Zan. "Platform and modular development mode for automobile products and implementation strategy" [J]. Automobile Technology, 2017(6).

[9] Hu Ying, Hu Kun. "Research on construction of technology innovation platform for new energy automobile industry in Shanghai" [J]. Science \& Technology Progress and Policy, 2012, 29(7):5458.

[10] Wang Xiuting, Chen Tianxiao. "Research on innovative service platform for automobile industry in the view of industry chain" [J]. Journal of Wuhan University of Technology (Information \& Management Engineering), 2010, 32(5):778-781.

[11] Tian Yupu. "Investigation and research on postgraduate teaching methods for physical education" [J]. Journal of Physical Education, 2010, 17(9).

[12] Wang Shuai. "Bloom mastery learning theory and educational application" [J]. Teacher Education Forum, 2007, 20(2):42-45. 